\title{
Studying a Long-Lasting Meteor Trail from Stereo Images and Radar Data
}

\author{
Roman V. Vasilyev ${ }^{1, * \mathbb{D}}$, Tatyana E. Syrenova ${ }^{1}$, Alexander B. Beletsky ${ }^{1}$, Maxim F. Artamonov ${ }^{1}$, \\ Eugeny G. Merzlyakov ${ }^{2}$, Aleksey V. Podlesny ${ }^{1}$ and Mark V. Cedric ${ }^{1}$ \\ 1 Institute of Solar-Terrestrial Physics SB RAS, 664033 Irkutsk, Russia; angata@iszf.irk.ru (T.E.S.); \\ beletsky@iszf.irk.ru (A.B.B.); artamonov.maksim@iszf.irk.ru (M.F.A.); pav1986@rambler.ru (A.V.P.); \\ mark7cedrick@gmail.com (M.V.C.) \\ 2 Institute for Experimental Meteorology, Science and Production Association "Typhoon", \\ 249030 Obninsk, Russia; evgmer@gmail.com \\ * Correspondence: roman_vasilyev@iszf.irk.ru
}

Citation: Vasilyev, R.V.; Syrenova, T.E.; Beletsky, A.B.; Artamonov, M.F.; Merzlyakov, E.G.; Podlesny, A.V.; Cedric, M.V. Studying a Long-Lasting Meteor Trail from Stereo Images and Radar Data. Atmosphere 2021, 12, 841. https://doi.org/10.3390/atmos 12070841

Academic Editor: Sergey Pulinets

Received: 17 May 2021

Accepted: 27 June 2021

Published: 29 June 2021

Publisher's Note: MDPI stays neutral with regard to jurisdictional claims in published maps and institutional affiliations.

Copyright: (c) 2021 by the authors. Licensee MDPI, Basel, Switzerland. This article is an open access article distributed under the terms and conditions of the Creative Commons Attribution (CC BY) license (https:// creativecommons.org/licenses/by/ $4.0 /)$.

\begin{abstract}
Unique observation of a long-lasting meteor trail of about half an hour duration is described. The trail resulted from a burning meteor from the Leonid storm flux in the middle latitudes over eastern Siberia. We describe three-dimensional morphological characteristics of both the meteor and the long-lasting trail using data from wide-angle CCD cameras. Additionally, we present the meteor and the trail radiolocation characteristics obtained with a meteor radar and ionosonde. The background dynamics of the upper atmosphere at the height where the long-lasting trail developed were observed using data from the meteor radar and Fabry-Perot interferometer. The obtained results allowed the conclusion that the dynamics of a long-lasting trail are conditioned by the wind. However, during the first minutes of trail development, it is possible that a high-speed component is present, resulting from explosion of the meteor body in the atmosphere. A primitive spectral analysis of the long-lasting trail's optical emissions and earlier studies point to hydroxyl molecules as a possible source of the glow. We believe the enhanced hydroxyl emission could be related to interaction of excited O(1D) oxygen atoms with meteor body water in the Earth's upper atmosphere.
\end{abstract}

Keywords: long-lasting meteor trail; airglow; upper atmosphere wind; all-sky camera; stereo image; Fabry-Perot interferometer; meteor radar; ionosonde

\section{Introduction}

Simultaneous observations of meteors using optical and radio instruments are widespread. Mainly, these investigations deal with the study of meteor fluxes, their dynamic characteristics, and the detection of meteoroid masses and structure. Recently, a comprehensive study devoted to comparison of stereoscopic and radio methods for meteor observations was performed. The authors collected a huge volume of statistics on meteor images obtained using fast cameras with image intensifiers together with data from the CMOR radar [1-3]. There, the authors estimated the efficiency of recording meteor parameters using both methods and settled on the ratio between the ionization coefficient and luminous efficiency. The study was performed for meteoroids with different chemical compositions and velocities. Similar research was performed in [4] using the MAARSY radar. In [5], the authors performed a multi-instrumental optical and radio study of non-underdense meteor trails, the ionization of which is significantly higher than the background level at the initial moment. However, the ionization does not cause specular reflection of the sounding radio signal from the meteor trail. In addition to a videocam, a 1-min time resolution ionosonde and SkiYMET meteor radar were also used. According to the authors, different rates of radio echo dissipation from non-underdense meteor trails are explained by the presence of nanoscale meteor dust. Subsequent study [6] was performed using significantly more observational data from SkiYMET (11 years of observations). It confirmed the key role 
of aerosols from meteoroids in the formation of long-lasting meteor echoes. The meteoroid mass threshold value needed to form a long-lasting meteor echo was evaluated as $0.02-0.03 \mathrm{~kg}$ in that work.

Radio echoes of ionized trails from meteors in the upper atmosphere are also used to determine horizontal wind speed and vertical wind shear in the mesopause region. Mostly, small meteors are used for this, with relatively weak ionization trails of about $1 \mathrm{~s}$ lifetime or less. Powerful meteors causing strong ionization with longer lifetimes (10 s or more) cannot be used to reconstruct the wind velocity vector using radar. In this case, the ionized area is non-isotropic and spatial dimensions are quite large. It is considered that the dynamics of such an area under vertical wind shear leads to complex radio echo interference, which is difficult to interpret. Nevertheless, there are works considering complex spectral compositions of radio echo. In reference [7], the authors demonstrate the radio echoes received by SESCAT radar from both non-underdense and specular long-lasting meteor trails with Doppler shift split into two components. The most probable reason for such bifurcation is the vertical wind shear dragging the trails in opposite directions, as the authors suggest. The study [8] based on data from the Sanya VHF radar, also indicates distortion of the radio echo from a long-lasting meteor trail as a consequence of neutral wind. Additionally, the authors suggest the existence of meteor dust, which can produce longer trail lifetimes. Based on data from the Gadanki MST radar, the authors of reference [9] speculate that apart from the reasons above, distortions in radio echoes from specular or non-underdense trails can be induced by meteoroid fragmentation.

The theory of long-lived meteor trail glowing and ionization dynamics was developed in a series of works by W. J. Baggaley based on naked-eye observations and the chemistry of atmospheric and meteor constituents. In reference [10], evaluations of ionization duration for elevations of 70-100 km were performed using metal oxide ion chemistry. Detailed study of the chemiluminescent processes of basic atmospheric constituents under meteor impact in reference [11] showed a negligible role for such types of processes in enduring meteor trails. Studies of the chemical process of two-step ozone dissociation with meteor body metals as catalysts in references $[12,13]$ led to the understanding that only $\mathrm{Na}$ and $\mathrm{K}$ atoms can produce long-lasting meteor trail glows in yellow and infrared. Further, reference [14] connected the brightness and duration of long-lived meteor trails based on sodium canalization of atmospheric ozone dissociation. Additionally, it should be noted that reference [15] studied the possibility of meteor trails generating red-orange emissions with atomic oxygen.

Optical instrumental observations of long-lasting meteor trails are rare because specific optical observations are basically performed within a small region of the sky and are limited due to weather conditions. Observational campaigns with the participation of amateur photographers facilitated detection of the morphological characteristics of long-lasting meteor trails $[16,17]$. The observed elevations where long-lasting meteor trails develop $(75-110 \mathrm{~km})$ and the large-scale spiral shapes emphasize the wind shear mechanism of trail formation. The lifetimes of long-lasting trails described in these studies are mostly of several minutes' (up to 10) duration. Nevertheless, long-lasting, self-glowing meteor trails (of up to $1 \mathrm{~h}$ ) have been observed with special instruments and their characteristics, physics, and chemistry described. In reference [18], a naked-eye observation of a long-lasting meteor trail was described. The meteor's trail elevation $(94 \mathrm{~km})$ and length $(30 \mathrm{~km})$ were evaluated with triangulation by witnesses from different points of observation. In addition to direct observational data for this event, the authors obtained photos with a wide-angle (fisheye) camera equipped with a narrowband optical filter with maximum transmission at the upper atmosphere sodium airglow wavelength. Further, the authors demonstrated sodium height profiles obtained with resonance sodium LIDAR, coinciding with data from eyewitnesses. Evaluation of the intensity of this event showed that for naked-eye observation, sodium only was not sufficient. In reference [19], the photochemical structure of long-lasting meteor trails was discussed on the basis of multi-spectral images. The authors concluded that in addition to sodium airglow, a significant component of the total 
intensity may include different bands of hydroxyl emissions, whereas molecular oxygen was unlikely as a probable reason for the meteor trail glow in the near infrared range.

In our work, we consider a unique, long-lasting meteor trail. The trail was observed simultaneously with two spaced wide-angle cameras, meteor radar, and ionosonde. Positions of the instruments are given in Figure 1. Earlier, characteristics of this meteor trail were studied in references [20,21]. In reference [20], the authors determined spatial and kinematic characteristics of the long-lasting trail and revealed features of its evolution using the Astrometry software [22]. The heights of meteor trail initiation and finalization were within $75-100 \mathrm{~km}$; brightness was about $-7.3 \mathrm{~m}$ apparent magnitude. It was shown that all parts of the long-lasting meteor trail propagated in a plane at a height of about $90 \mathrm{~km}$ and at a rate of $320 \mathrm{~m} / \mathrm{s}$. It was hypothesized that such a movement could not be explained by the wind. In [21], parameters of the long-lasting meteor trail were compared with ionosonde observations of the trail. Here, it was supposed that the neutral and ionized components of the long-lasting meteor trail moved with different velocities. In our work, we carried out a detailed analysis of the long-lasting meteor trail images while accounting for aberrations in wide-angle optical systems. Stereoscopic analysis was performed, and the data obtained were compared with radio echoes using meteor radar and ionosonde.

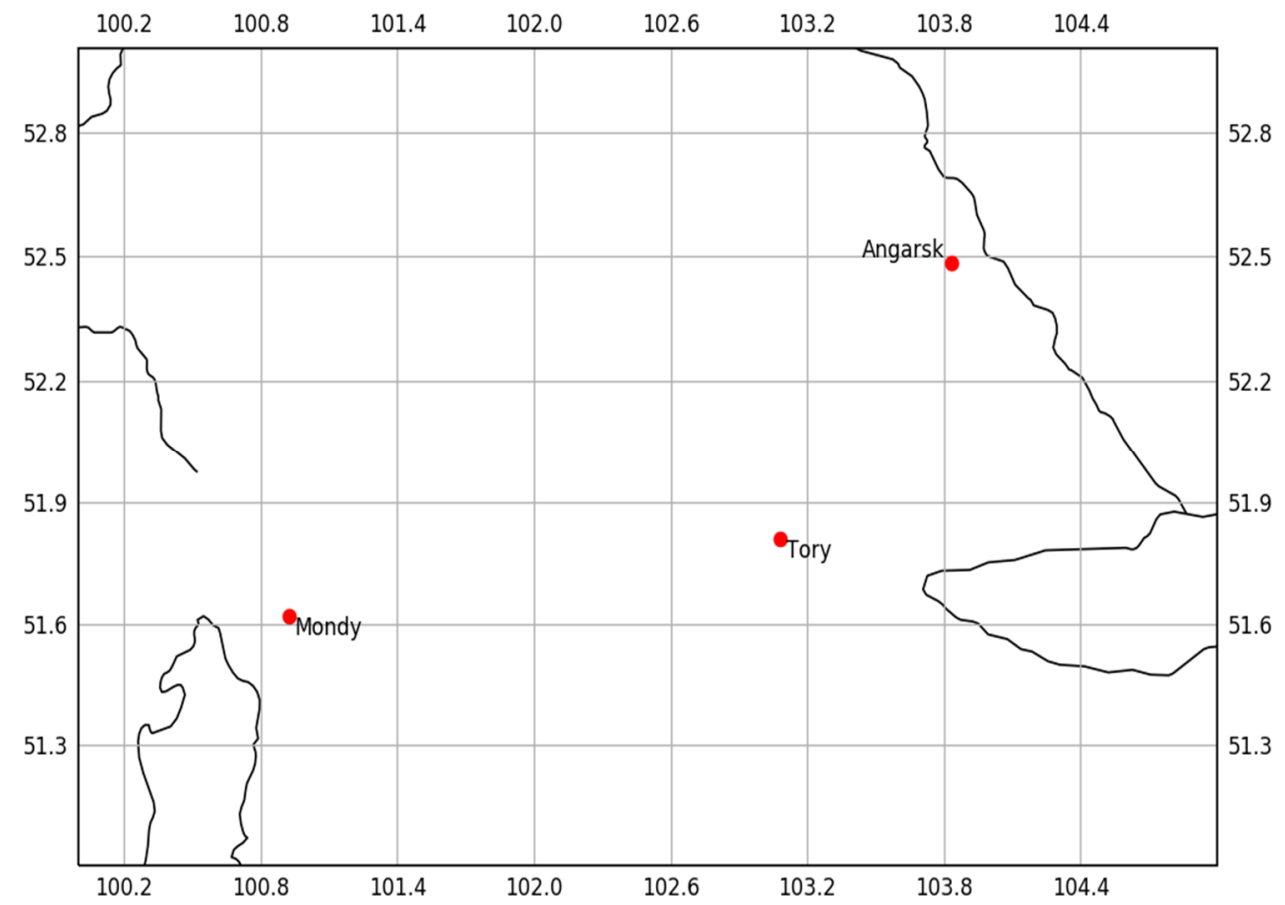

Figure 1. Geometry of observations. Wide-angle cameras are located in Tory (KEO Sentinel) and Mondy (SBIG Allsky-340). The meteor radar is located in Angarsk. Ionosonde-MS is located in Tory.

\section{The Instruments Used and Data Analysis}

\subsection{Stereoscopic Analysis Using Wide-Angle Cameras}

The cameras we used were spaced about $150 \mathrm{~km}$ apart. The first one was the KEO Sentinel all-sky camera in the ISTP SB RAS Geophysical observatory near Tory village $\left(51.8^{\circ} \mathrm{N}, 103.1^{\circ} \mathrm{E}, 670 \mathrm{~m}\right.$ height); it was intended to record the spatial distribution of $630 \mathrm{~nm}$ emissions. The optical system field of view was $145^{\circ}$, the viewing direction toward the zenith, the interference filter full width at half maximum was $2 \mathrm{~nm}$, and exposure was $60 \mathrm{~s}$ (http:/ / atmos.iszf.irk.ru/ru/data/keo, accessed on 29 June 2021).

The second wide-angle GRB camera, Allsky-340 from the SBIG, was in the ISTP SB RAS Sayan solar observatory near Mondy village (51.6 ${ }^{\circ} \mathrm{N}, 100.9^{\circ} \mathrm{E}, 1992 \mathrm{~m}$ height). The employed photosensor was a Kodak KAI-0340 $640 \times 480$ pixel (pixel size $7.4 \mu \mathrm{m}$ ) fish-eye lens with $4 \mathrm{~mm}$ focal length and 1:4 relative aperture, providing a $185^{\circ} \times 145^{\circ}$ field of view. Image scale in zenith was $18^{\prime}$ / pixel. Exposure was changed automatically for different light 
conditions; in the nighttime it was mostly about $60 \mathrm{~s}$, and the interval between snapshots was $140 \mathrm{~s}$.

The meteor trail was observed on 18 November 2017 just after finalization of the initial meteor at 22:23:19 UT (Figure 2). Brightness of the initial meteor was significantly higher than that of other objects in the field of view. The long-lasting meteor trail was less bright, but it was clearly distinguished on the background night sky. The trail began as a local glowing structure at the middle of the initial meteor. The trail was arc-shaped, brightest in the middle part. The trail gradually increased over time and became less distinguished in the sky. Full duration of the observation (about $40 \mathrm{~min}$ ) was longer than the trail duration observed by Clemesha [19] and consistent with the trail duration observed by Kelley [18].

Simultaneous trail recording with two digital cameras allows us to detect spatial characteristics of the observed object by means of stereoscopic analysis. Stereoscopic analysis of celestial objects is based on triangulation of similar parts of the object seen from different points on the Earth's surface. On digital images, similar parts of the object are defined as groups of pixels with regular (pixel) coordinates. Therefore, to implement stereoscopic analysis, one needs to define precisely the conformity between pixel position in the image coordinates and directions in horizontal coordinates with the center in the camera position [23]. Aberrations of wide-angle (fish-eye) systems may cause significant image distortions that hamper binding of pixel position to the azimuth and elevation in horizontal coordinates. The ambiguity related to non-precise orientation of the camera will also introduce errors. Therefore, it is essential to build an analytical model for unambiguous collation of pixel coordinates on the image and directions in relevant horizontal coordinates.

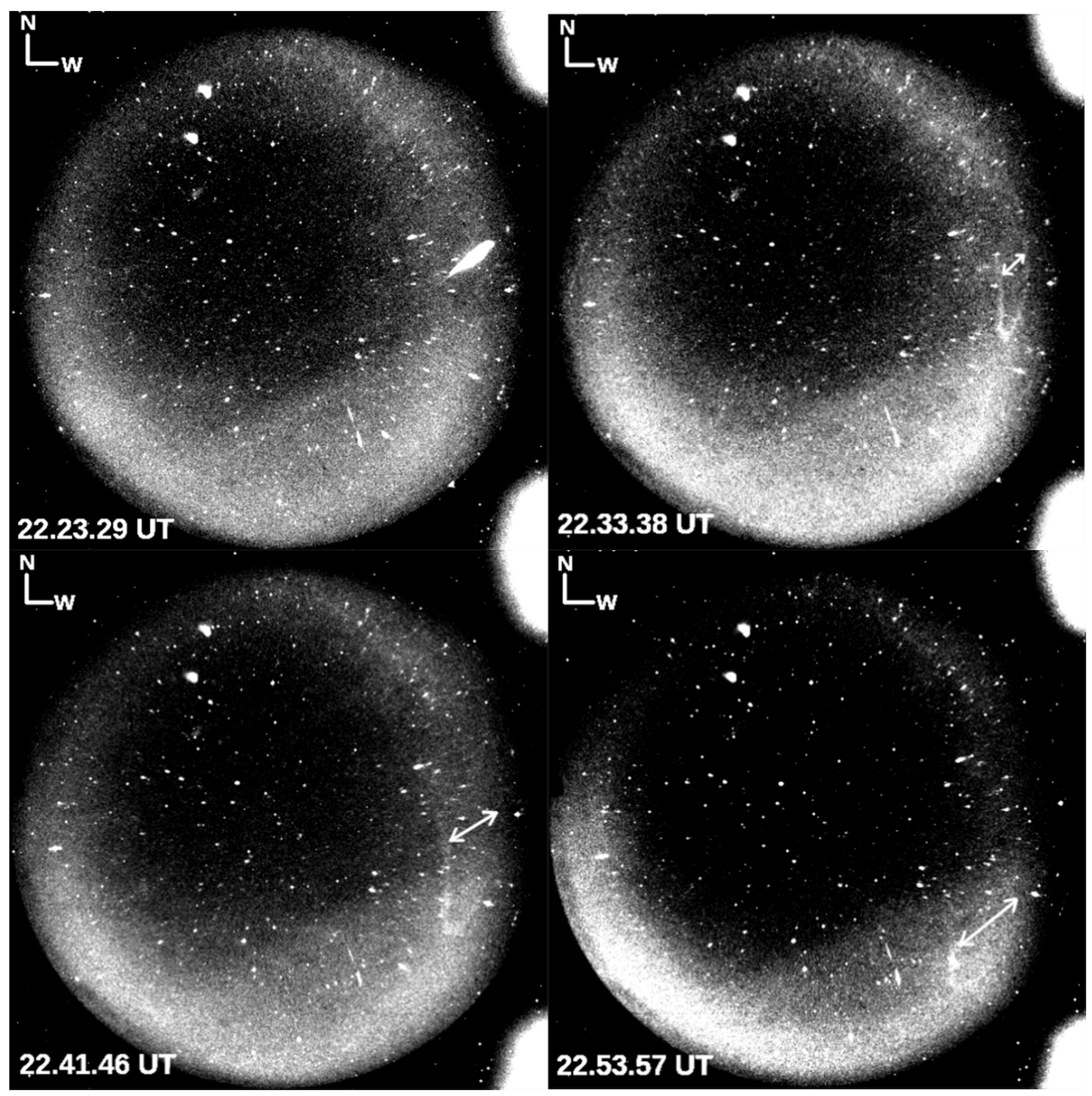

Figure 2. Cont. 


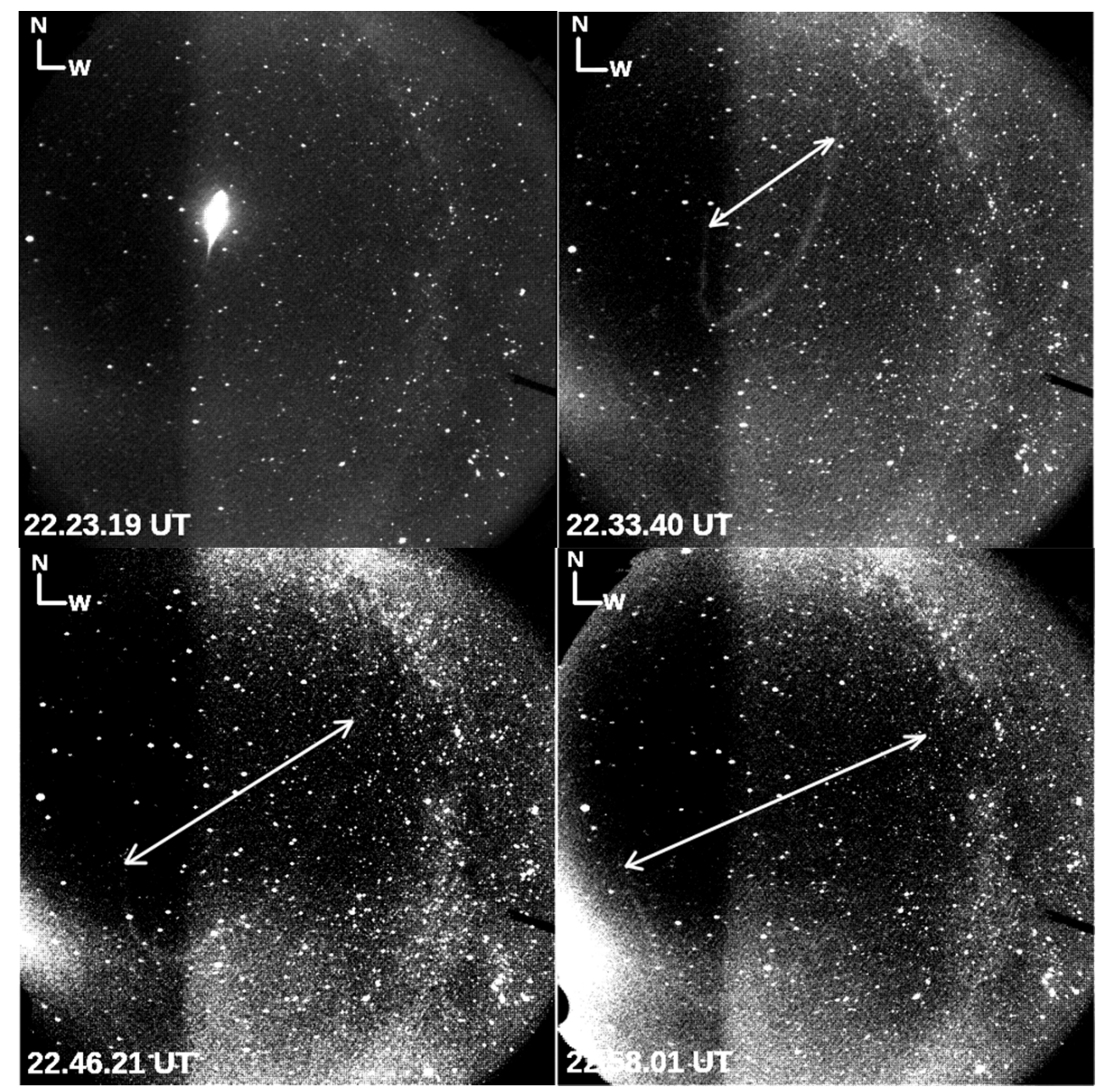

Figure 2. Frames obtained at close points of time using optical systems KEO Sentinel (top row) and AllScheme 340 (bottom row) on 18 November 2017. Exposure, $60 \mathrm{~s}$.

The analytical model can be expressed as follows:

$$
\begin{gathered}
\varphi(x, y)=\tan ^{-1}\left(\frac{y-y_{0}}{x-x_{0}}\right)+\varphi_{0} \\
\theta(x, y)=a r^{2}+b r+c \\
r=\sqrt{\left(x-x_{0}\right)^{2}+\left(y-y_{0}\right)^{2}}
\end{gathered}
$$

Expression (1) defines the azimuthal angle accounting for the camera arbitrary rotation by $\varphi_{0}$, where $x, y$ are the pixel coordinates on the image and $x_{0}, y_{0}$ are the zenith position in these coordinates. Expression (2) defines the zenith angular distance of a pixel. It can be written using the distance between the arbitrary pixel and zenith on the matrix expressed by (3). Dependence (2) is a quadratic polynomial dependence of distance (3) with constant coefficients $a, b$, and $c$. Such dependencies along with exponential representations for wideangle cameras were used in [24-26]. In [27], it was shown that the quadratic polynomial dependence is of higher precision.

The relationship between the pixel and horizontal coordinate systems can be presented using complex numbers:

$$
z=x+i y=\operatorname{Re}\left[\theta(x, y) e^{i \varphi(x, y)}\right]+i \operatorname{Im}\left[\theta(x, y) e^{i \varphi(x, y)}\right]
$$


where $\theta(x, y)$ and $\varphi(x, y)$ are defined by expressions (1-3). Constant coefficients in (1-3) can be retrieved by the least-square method using (4) as a model. Coordinates of the stars in the horizontal system and their relevant positions on the image will be the benchmark coordinates for this procedure. We selected 105 objects on the KEO Sentinel image and 72 objects on the Allssky-340 image uniformly spread over the field of view. The model was adapted to this data sets using the Levenberg-Marcquardt algorithm [28]. The error was calculated as

$$
S=\sum_{n=0}^{M}\left|\theta_{n} e^{i \varphi_{n}}-\theta\left(x_{n}, y_{n}\right) e^{i \varphi\left(x_{n}, y_{n}\right)}\right|
$$

for the elevation angle and azimuth of the $n$-th object from the catalogue and relevant pixel coordinates. The method errors were evaluated from dispersion of stellar coordinates obtained from the described model relative to their catalogue values. These errors are about 1 degree, which is quite acceptable for most geophysical applications using such cameras. Projection of angular uncertainty obtained by reconstructed and catalogue stellar object data, to the surface in our case, brings the latitude and longitude errors to about $2^{\prime}$ and less than $1^{\prime}$, respectively.

It is convenient to analyze geophysical events in coordinates bound to the Earth's surface. One can connect celestial images of the meteor or long-lasting meteor trail obtained from two ground-based positions in terrestrial coordinates and obtain spatial characteristics of the objects. To do this, the position of each snapshot pixel was converted into horizontal coordinates using expressions (1-3) and the resultant constant coefficients. Then, using the obtained horizontal coordinates and geographic coordinates of the camera, we can solve a direct geophysical problem accepting Earth as an ideal sphere and obtain projections of the meteor or meteor trail on the Earth's surface from some height. After that, one has to superimpose the projections for equal heights from snapshots obtained in both points at the same time. If some part of the meteor or meteor trail on the first projection coincides with some part of the meteor or meteor trail on the second projection, this means the coinciding part of the trail has the same geographic coordinates for the chosen height.

One can obtain the object spatial structure by constructing projections in geographic coordinates for a set of heights. Figure 3 illustrates the method for generating a threedimensional picture of the initial meteor. At this stage, images with projections were processed manually because automation is rather difficult due to the low signal-to-noise ratio and the special algorithms required to distinguish the needed object from stars, nonuniform background glow, etc. Determination of errors in the calculation of heights, in our case, was difficult. Because the method has been tested so far on only one event, there may be unaccounted for systematic errors.

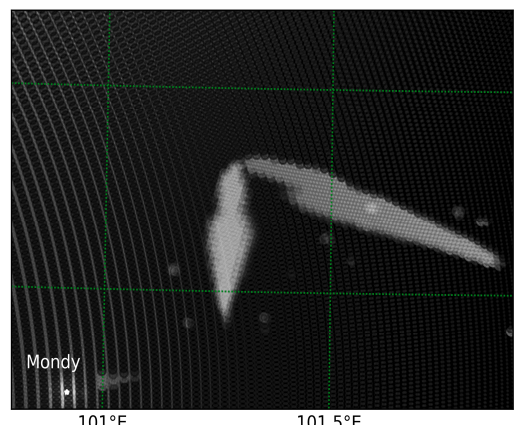

$101^{\circ} \mathrm{E}$

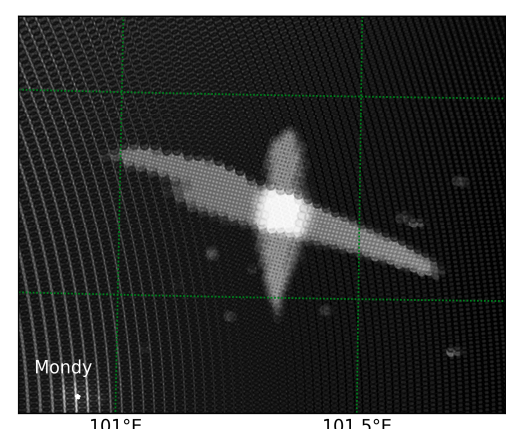

$101^{\circ} \mathrm{E}$

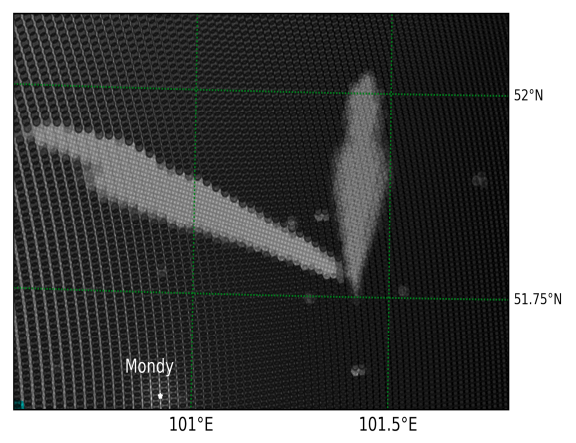

Figure 3. The meteor projection from the KEO Sentinel and Allsky-340 cameras on the Earth's surface at distances of 78.92 and $111 \mathrm{~km}$ (left to right), respectively.

Having analyzed the intersecting parts of the meteor for different heights, we determined that the meteoroid was moving northward at $60^{\circ}$ to the horizon. The meteor initiated at the height of $111 \mathrm{~km}$ and finalized at $78 \mathrm{~km}$; the full length of the track was about $38 \mathrm{~km}$. The non-uniformity of the meteor near the middle part, just before finalization, 
was distinctively seen in Figure 3. Apparently, this is due to meteoroid fragmentation. Coordinates of some trajectory points of the meteor are given in Table 1.

Table 1. Meteor coordinates retrieved from data in Figure 3.

\begin{tabular}{cccc}
\hline & Latitude, Degrees & Longitude, Degrees & Height, $\mathbf{k m}$ \\
\hline initiation & 51.78 & 101.38 & 111 \\
\hline fragmentation & 51.89 & 101.31 & 81 \\
\hline middle part & 51.85 & 101.33 & 92 \\
\hline finalization & 51.94 & 101.30 & 78 \\
\hline
\end{tabular}

We applied the same method for snapshots of a long-lasting meteor trail maximally coinciding in time (Figure 4) and defined its spatial dynamics. The trail developed within the height range of 88-106 km. Right after the meteor finalization, initial horizontal size of the long-lasting trail was about $10 \mathrm{~km}$. Prior to full dissipation, its horizontal dimensions were $375 \mathrm{~km}$ in the north-south directions and $140 \mathrm{~km}$ in the east-west directions. Table 2 contains precise information about spatial coordinates of different parts of the long-lasting meteor trail and their dynamics. The obtained data indicate that the trail shape was a spiral whorl extended in height rather than a flat arc. Assuming that the considered long-lived trail retains its shape in a certain range of altitudes of about $10 \mathrm{~km}$, for several consequent measurements, we could evaluate that in the roughest approximation the statistical error estimate (uncertainty without systematic errors mentioned above) was less than $10 \mathrm{~km}$.

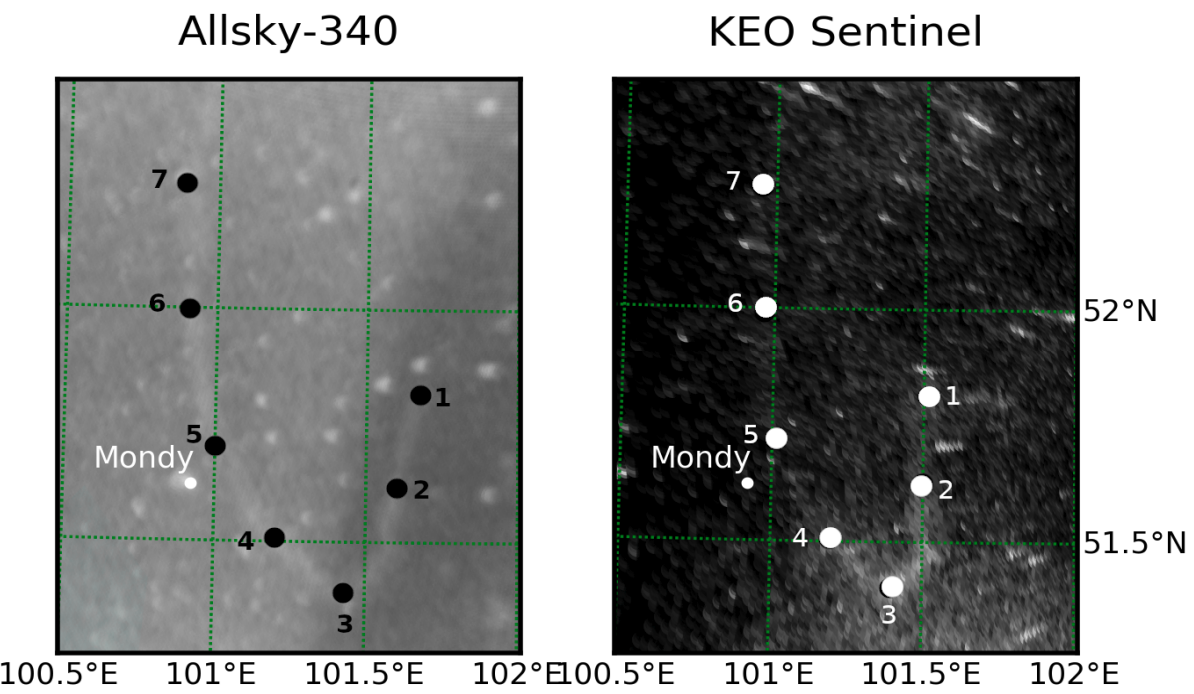

Figure 4. Projections of images from two cameras (Allsky-340 on the left, KEO Sentinel on the right) onto the Earth's surface from the $94 \mathrm{~km}$ height at 22:33:38 UT. The numbered points are the parts of the meteor trail, for which projections on the Earth's surface coincide at different heights.

Table 2. Space and time dynamics of a long-lasting meteor trail from stereoscopic data analysis.

\begin{tabular}{|c|c|c|c|c|c|c|c|c|c|c|c|c|}
\hline & \multicolumn{4}{|c|}{ Latitude, Degrees } & \multicolumn{4}{|c|}{ Longitude, Degrees } & \multicolumn{4}{|c|}{ Height, km } \\
\hline $\mathrm{N}^{\mathrm{UT}}$ & 22:31:20 & 22:41:42 & $22: 48: 42$ & $22: 53: 21$ & 22:31:20 & 22:41:42 & 22:48:42 & 22:53:21 & 22:31:20 & 22:41:42 & 22:48:42 & 22:53:21 \\
\hline 1 & 51.8 & 51.75 & 51.3 & 51.1 & 101.48 & 101.8 & 101.85 & 102 & 88 & 90 & 93 & 95 \\
\hline 2 & 51.7 & 51.4 & 51 & 50.5 & 101.4 & 101.7 & 101.8 & 101.5 & 90 & 93 & 95 & 104 \\
\hline 3 & 51.5 & 51.06 & 50.75 & 50.7 & 101.3 & 101.45 & 101.5 & 101 & 93 & 97 & 98 & 104 \\
\hline 4 & 51.64 & 51.25 & 51 & 51 & 101.13 & 101 & 101 & 100.6 & 93 & 97 & 100 & 104 \\
\hline 5 & 51.72 & 51.65 & 51.45 & 51.5 & 101 & 100.6 & 100.45 & 100.25 & 93 & 97 & 103 & 104 \\
\hline 6 & 52 & 52 & 52 & 52 & 100.9 & 100.5 & 100.2 & 100 & 96 & 100 & 104 & 106 \\
\hline 7 & 52.27 & 53 & - & - & 100.95 & 100.5 & - & - & 97 & 100 & - & - \\
\hline
\end{tabular}




\subsection{Primitive Spectral Analysis Using Data from All-Sky Cameras}

The only device for evaluating spectral composition of the event in question was the Allsky-340 RGB camera. Relative intensity of the objects in different color channels indicated that the initial meteor glow was distributed over the entire visible spectral range. The spectral composition of the long-lasting meteor trail was mainly in the yellow part of the visible range (red and green channels of the camera). The trail image in the camera blue channel was clearly seen only in the first snapshot made a few minutes after the initial meteor. In the red and green channels, the trail image was clearly seen on the sky background for $40 \mathrm{~min}$ after the meteor. The trail glow intensity decreased by a factor of 3 during $\sim 10 \mathrm{~min}$ of observation. The ratio between the intensities in the red and green channels was approximately the same during the entire observation. It should be noted that the spectral characteristics of the camera red and green channels were rather wide and partially overlapped. Therefore, in the first approximation, one can conclude that these two channels recorded the long-lasting meteor trail in green, yellow, and red spectral ranges.

The KEO Sentinel wide-angle camera was equipped with a $630 \mathrm{~nm}$ central wavelength narrowband light filter, which significantly rejects the continuum contribution and eliminates other spectral lines of the night airglow. Using the KEO Sentinel, we obtained clear images of the long-lasting meteor trail during a time interval comparable with the Allsky340 observation time. Therefore, the long-lasting meteor trail glow appeared basically in the green, yellow, and red spectral ranges.

\subsection{Meteor Radar Data}

Radiolocation data were obtained using the MK-31 meteor radar near Angarsk (52.5 $\mathrm{N}, 103.8^{\circ} \mathrm{E}, 433 \mathrm{~m}$ height). The radar's main characteristics are as follows: $46 \mathrm{MHz}$ frequency, $8 \mathrm{~kW}$ pulse power, $100 \mu$ s pulse duration, $400 \mathrm{~Hz}$ repetition rate, and location precision of $\pm 2 \mathrm{~km}$. The MK-31 is dedicated to retrieving upper atmosphere horizontal wind averaged over the height. Wind from radar data is averaged near $\sim 90 \mathrm{~km}$ (the maximum of ionization from meteors). Additional information is available at: https://www.rpatyphoon.ru/products/software-hardware/mk31.php, accessed on 29 June 2021. Figure 5 presents radio echo characteristics for the observed long-lasting meteor trail. Duration of the radar observation (about $2 \mathrm{~min}$ ) was significantly shorter than that with cameras. During these $2 \mathrm{~min}$, the range to the long-lasting meteor trail was changing within $232-237 \mathrm{~km}$. The time profile was not monotonic. Initially, the range increased, then decreased smoothly, and in the final stage increased again within the limits above. The Doppler shift of the working frequency has at least two components as described in [7]. One of the components (green line in Figure 5, left panel) crossed the zero line and corresponded to variation in frequency around the central one $(46 \mathrm{MHz}) \pm 10 \mathrm{~Hz}$. Variation of target velocity in this case will be from -65 to $65 \mathrm{~m} / \mathrm{s}$. Another Doppler component (blue line in Figure 5, left panel) comprised two parts: varying and constant. The frequency variation from zero to $-30 \mathrm{~Hz}$ from the central frequency in the first $30 \mathrm{~s}$ corresponded to the target moving with $6.5 \mathrm{~m} / \mathrm{s}^{2}$ acceleration. Additionally, the constant component (stable frequency shift $-30 \mathrm{~Hz}$ ) corresponded to $\sim 200 \mathrm{~m} / \mathrm{s}$ for the remaining $1.5 \mathrm{~min}$ of observation. Dynamics of the radio echo amplitude in the initial part and in fast variations generally matched with the dynamics of the radio echo from the long-lasting meteor trail in Figure 1c-e in reference [6] and Figure 10 in reference [5]. A more exact comparison can be made with Figure 2 in reference [6] because the whole signal is presented. The integral or maximal amplitude of the signal varied comparatively (growth in first $10 \mathrm{~s}$ and decay in last $30 \mathrm{~s}$ ) as in Figure 5 (growth in first $15 \mathrm{~s}$ and decay in last $60 \mathrm{~s}$ ). The same similarity of signals can also be seen in Figure 1 (left panels) in [7] and in Figure 5. 

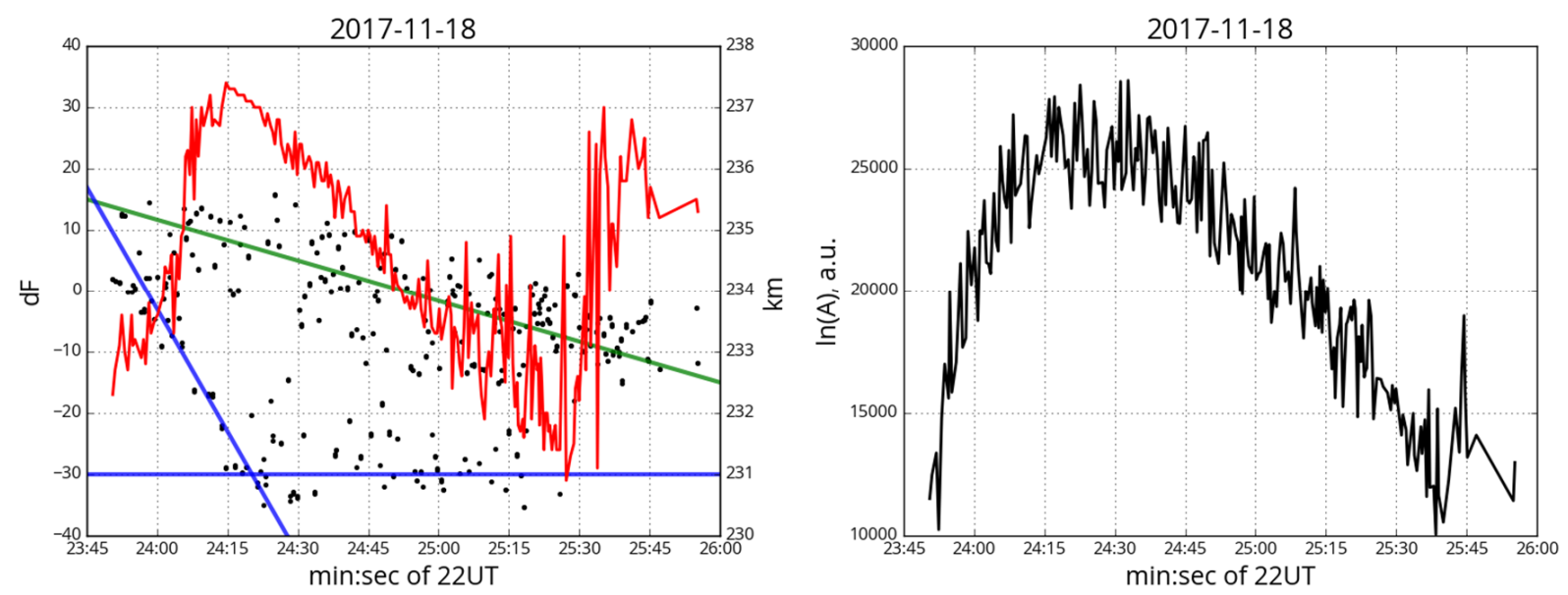

Figure 5. (Left): Range (red line) and Doppler shift (black dots) of the long-lasting meteor trail observed with the MK-31 radar; green and blue lines show the trends of different components of signal Doppler shift. (Right): Dynamics of the reflection amplitude in arbitrary units.

\subsection{Ionosonde Data}

The long-lasting meteor trail was also detected in the ionosonde radiolocation data. The vertical and oblique chirp sounding Ionosonde-MS is a part of the ISTP SB RAS radio sounding network. Transmitters of the network are located near Usolye-Sibirskoye, Norilsk, Khabarovsk, and Magadan. Ionosonde-MS not only receives the remote transmitter signals, it also performs vertical sounding of the ionosphere with $1 \mathrm{~min}$ time resolution (http: / / dep1.iszf.irk.ru/CHIRP_ionogrames, accessed on 29 June 2021). The long-lasting meteor trail appeared on ionograms as a sporadic E layer with very short lifetime. Ionograms related to this event were discussed in [21]. The ionosonde does not adapt for registration of meteor echoes. Such types of signals for the ionosonde are rather weak because reflected radio waves mostly come from low elevation angles and are not suitable for analysis. Meteor echo duration depends on the measure of ionization, corresponding frequency, signal to noise ratio, and energetic potential of the ionosonde. Energetic potential of the ionosonde in turn depends on power of transmitter, antenna matching, and antenna gain and directivity pattern. All of the values vary in frequency range and direction, especially at low elevation angles. Nevertheless, one can note some details of the registered long-lived meteor trail signal. The longest reflection duration was about $10 \mathrm{~min}$. at $3.5 \mathrm{MHz}$. A near$10 \mathrm{MHz}$ reflection was present for $6 \mathrm{~min}$, and in the 13-17 MHz range, a reflection lasted about $4 \mathrm{~min}$. The gaps in amplitude within the $5-8 \mathrm{MHz}$ and $10-12 \mathrm{MHz}$ ranges and below $2.5 \mathrm{MHz}$ were due to minima in the directivity pattern and a poor signal to noise ratio. The registered reflection gradually dissipated from high electron density $>5 \times 10^{6} \mathrm{~cm}^{-3}$ to background values of $\sim 5 \times 10^{5} \mathrm{~cm}^{-3}$. The apparent height of the reflection during observation was within $135-190 \mathrm{~km}$. We plotted the amplitude map for this height range, where the dynamics of critical frequency were more clearly visible (Figure 6). One can see that through almost half the observation time, the critical frequency was near the upper boundary of the ionosonde working frequency range. Unfortunately, it was impossible to analyze the situation in more detail. The long-lasting trail developed at a noticeable distance from the ionosonde main lobe, where the signal-to-noise ratio prevents tracing the dynamics of critical frequency. Nevertheless, this lifetime (order of $10 \mathrm{~min}$ ) of the observed long-lasting meteor trail corresponded to the lifetimes of trails observed in [5]. 


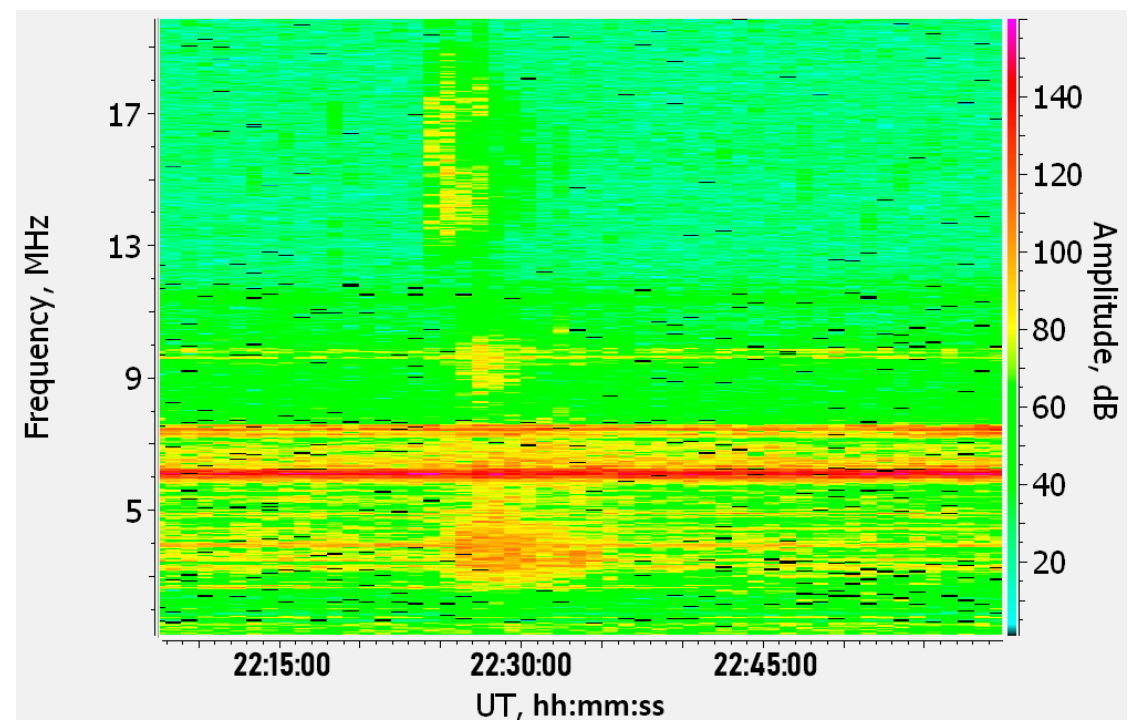

Figure 6. A-map of electron density dynamics obtained from the ionosonde data. The amplitudes are averaged within the heights $135-190 \mathrm{~km}$ range containing the signal of the long-lasting meteor trail.

\subsection{Data on Horizontal Wind at the Height of Long-Lasting Meteor Trail}

To evaluate the dynamics of the long-lasting meteor trail due to the wind field, we used velocities of neutral wind obtained with a KEO Scientific "Arinae" Fabry-Perot interferometer (FPI) and the MK-31 radar. The interferometer is located in the geophysical observatory near the KEO Sentinel wide-angle camera and Ionosonde-MS. The device is intended for spectroscopic observation of airglow in the night atmosphere (http:/ /atmos. iszf.irk.ru/ru/data/fpi, accessed on 29 June 2021). At the heights close to the long-lasting meteor trail, the interferometer detected a $557.7 \mathrm{~nm}$ green line for atomic oxygen at the $97 \mathrm{~km}$ height. It also detected an $843 \mathrm{~nm}$ infrared line for hydroxyl emissions from Meinel band 6-2 glowing at $87 \mathrm{~km}$ [29]. The etalon diameter was $70 \mathrm{~mm}$ with a $15 \mathrm{~mm}$ air gap, the focus distance was $310 \mathrm{~mm}$, and the CCD matrix was $1024 \times 1024$ pixels with pixel size $1.3 \times 1.3 \mu \mathrm{m}$ cooled down to $-70^{\circ} \mathrm{C}$. More details about the device can be found in reference [30].

From Figure 7 one can see that meridional velocities near the observed event were quite different and oppositely directed. At the $97 \mathrm{~km}$ height, the wind was blowing northnorthwest, changing to north-northeast in half an hour at about $80 \mathrm{~m} / \mathrm{s}$, while at $87 \mathrm{~km}$, the wind was directed southeast at about $10 \mathrm{~m} / \mathrm{s}$. The velocities detected with the meteor radar at the $\sim 90 \mathrm{~km}$ height apparently indicated some intermediate state between the wind velocities obtained using FPI at different heights.
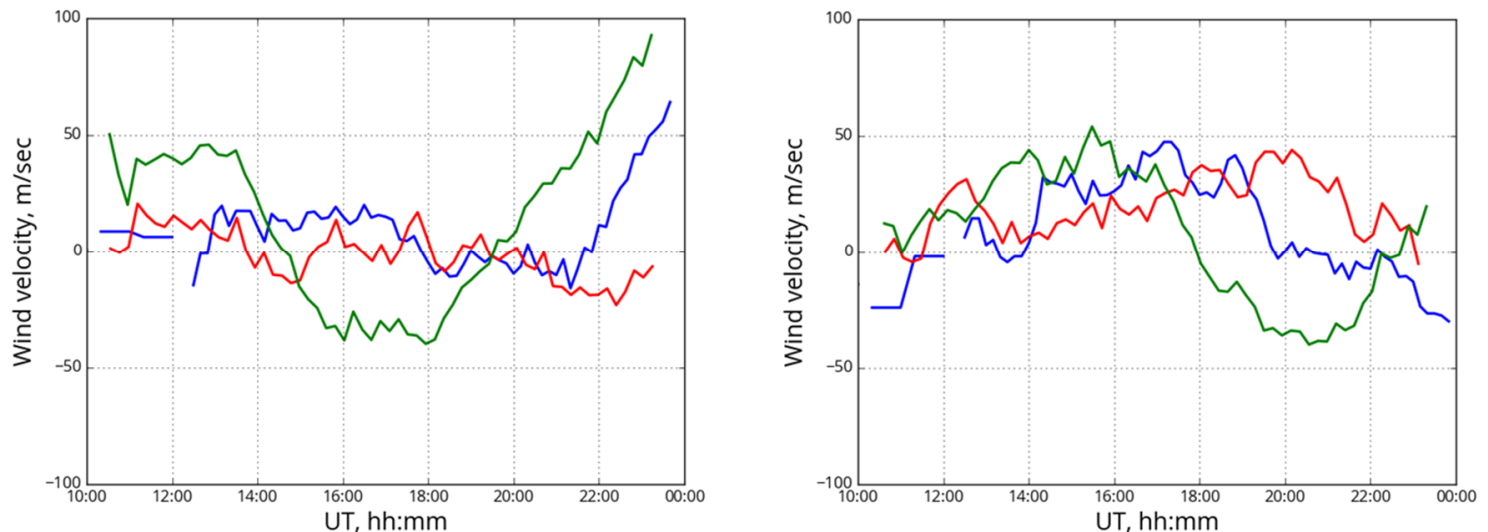

Figure 7. Velocities of meridional (left) and zonal (right) winds reconstructed from green (557.7 $\mathrm{nm}$, green) and IR (843 nm, red graph) emission lines using FPI, and from the meteor radar data (blue graph) for the night 18/19 November 2017. 


\section{Discussion}

Development of the long-lasting meteor trail started at 22:24:30 UT. The trail dissipated amidst stars at 22:55:41. The trail was moving at heights in the range of $88-106 \mathrm{~km}$. The trail glow could not be explained by solar radiation scattering on dust particles from the meteoroid fragmentation. This is because the solar angle with respect to the horizon required to illuminate the object in coordinates given in Table 2 within the specified time interval must have been at least $-10^{\circ}$. For these time points in the given coordinates, the Sun was at a height of about $-20^{\circ}$ and about $-16^{\circ}$ with respect to the horizon.

Primitive spectroscopic analysis demonstrate that the spectrum of the long-lasting meteor glow was mainly in the green, yellow, and red regions. In these regions, near the height of trail development defined by stereoscopy, the airglow comprised atomic oxygen $(557.7 \mathrm{~nm}, 97 \mathrm{~km})$, sodium $(589 \mathrm{~nm}, 90 \mathrm{~km})$, and hydroxyl (basically red and infrared ranges) emissions from photochemical reactions. In reference [20], sodium was considered to be the most probable reason for the glow. As mentioned above, the hypothesis regarding sodium emissions was also made in reference [18]. However, Clemesha [19] extended the obtained result and showed that hydroxyl emissions contributed significantly to the glow of the long-lasting meteor trail. The KEO Sentinel wide-angle camera is equipped with a narrowband light filter with a transmission band that is still wide enough to record one of the lines of hydroxyl emission (9-3), $630.36 \mathrm{~nm}$. It took the camera quite long to record the meteor trail, and this may indirectly confirm the presence of the hydroxyl component in the trail's glow.

According to the MK-31 meteor radar data, the range to the meteor was $231-237 \mathrm{~km}$. The radar to meteor distance calculated from the coordinates obtained by stereoscopy yielded a value of $\sim 220 \mathrm{~km}$. Unsuspected systemic errors may be a possible reason because the method for detecting directions from all-sky camera data had not been checked using different datasets (snapshots of the same objects by both cameras).

Using data from Table 2, one can evaluate the velocity of the trail's horizontal expansion. The trail expanded eastward and westward at an average velocity of $25-30 \mathrm{~m} / \mathrm{s}$, and southward at $\sim 70 \mathrm{~m} / \mathrm{s}$. Unfortunately, we could not determine northward velocity reliably due to a lack of data. It should be noted that the velocities obtained from stereoscopy were similar to the velocities of ionized trail obtained in reference [21] and were close to the horizontal wind velocities obtained with the Fabry-Perot interferometer and meteor radar in our study (Figure 7).

We could not precisely define the vertical wind shear in this work because the interferometer and radar obtained wind velocities averaged in height within about a 10-km range near the airglow maximum or meteor ionization. Nevertheless, the presented trends in variation of horizontal wind velocities for three height ranges indicated significant wind shear in that range. The meridional velocities for the 87 and $97 \mathrm{~km}$ heights were the opposite, and the zonal wind velocities at 90 and $97 \mathrm{~km}$ were opposite, also. Moreover, we could say that at $87 \mathrm{~km}$, the wind velocity vector was mainly directed southward. At $90 \mathrm{~km}$, it was directed northwest, and at $97 \mathrm{~km}$, the wind velocity vector was directed northeast. This is consistent with the mechanism of meteor trail formation due to wind shear according to data in Table 2. A schematic view of the spatial distribution of the long-lived meteor trail with wind shear is shown in Figure 8.

It is difficult to compare data from the MK-31 radar and wide-angle cameras in this work. First, we were not certain that the ionized and glowing parts of the long-lasting meteor trail were the same object at the initial stage of its development. This could also be partially indicated by the difference in ranges determined with the radar and stereoscopy discussed above. Second, the duration of the joint recording of the event joint did not exceed 2 min. During this time, the Allsky-340 was in a stand-by mode waiting for the next exposure, and the KEO Sentinel took only three snapshots. Resolution of the long-lasting meteor trail on the snapshots was very low and stereoscopic analysis was not possible; hence, we could make only rough evaluations. 


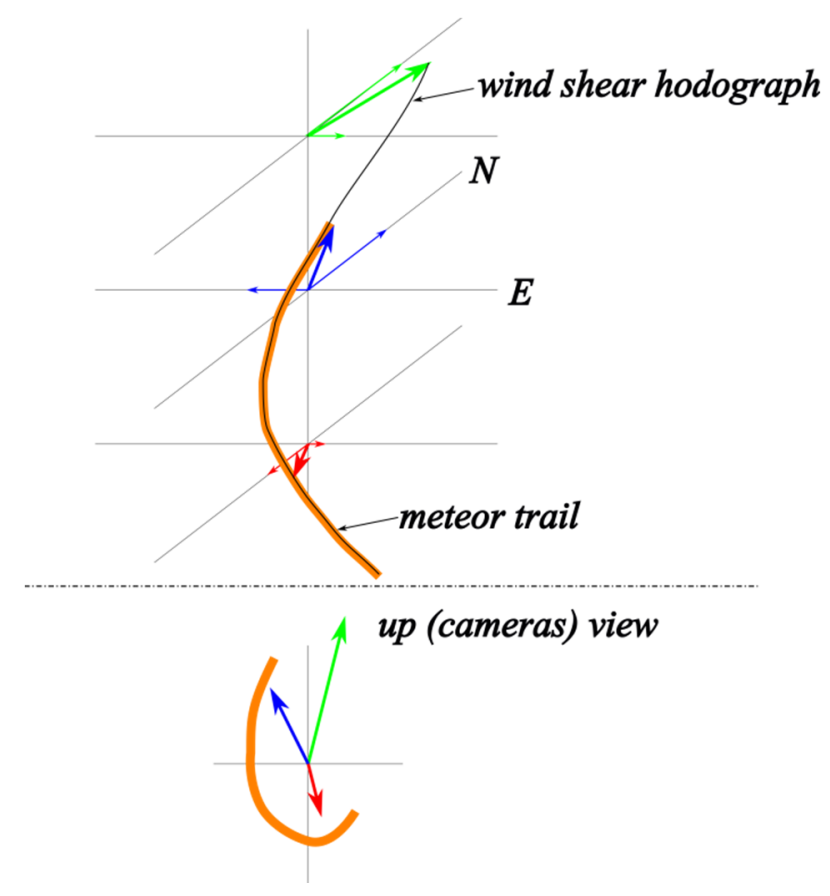

Figure 8. Schematic view of the spatial distribution of the trail (yellow) wind directions on the different levels (colored arrows) and wind shear hodograph (black curve).

Evaluation of the trail instantaneous velocity at the initial stage of development for projection onto the Earth surface from an average height of $\sim 90 \mathrm{~km}$ shows that the trail moved in all directions with deceleration. Moreover, the trail propagated along the northsouth direction with a velocity approximately 2 times higher than along the east-west direction. The averaged radial velocity dropped from an initial $100-200 \mathrm{~m} / \mathrm{s}$ to the values obtained above using data in Table 2 . The radial velocity approximately corresponded to the velocity of one of the Doppler shift components in the radar echo. Apparently, this component corresponded to the part of the long-lasting trail propagating along the line of sight toward the radar. The second Doppler component crossed the zero line. Probably this Doppler component corresponded to the trail part crossing the line of sight. Figure 9 shows the projection of the long-lasting meteor trail plotted from KEO Sentinel data just after the radar echo faded out from the trail. The southern part of the trail has shifted from its initial position by about $15^{\circ}$ if we look from the radar. Projection of the $65 \mathrm{~m} / \mathrm{s}$ velocity at this angle to the line of sight is about $250 \mathrm{~m} / \mathrm{s}$, which is close to the above radial velocities. Obviously, in our case, a more thorough analysis of the situation is required, which is only possible when there is new information about the event.

The presence of dust particles explains the lasting duration of the ionized trail component dissipation recorded with ionosonde [5]. Dust particles reduce the diffusion rate, which leads to a longer duration of radio echoes from meteor trails. The other process responsible to the long ionization could be the chemical dynamics of meteoroid metal ions in the atmosphere. Reference [10] studied dynamics of ionization and found that at $90 \mathrm{~km}$ height, the lifetime of electrons responsible for HF reflections can be as long as several hundreds of seconds. Moreover, both processes can explain the lasting glow of the meteor trail itself.

The glow is induced by photochemical reactions of the meteor dust components with the air of the upper atmosphere. If the meteor substance moves as a sublimating dust containing water and sodium, this substance distributed in the upper atmosphere may provide both the rapidly disappearing, sporadic Es observed with the ionosonde, and the spectral composition of the long-lasting meteor trail glow as described above. 


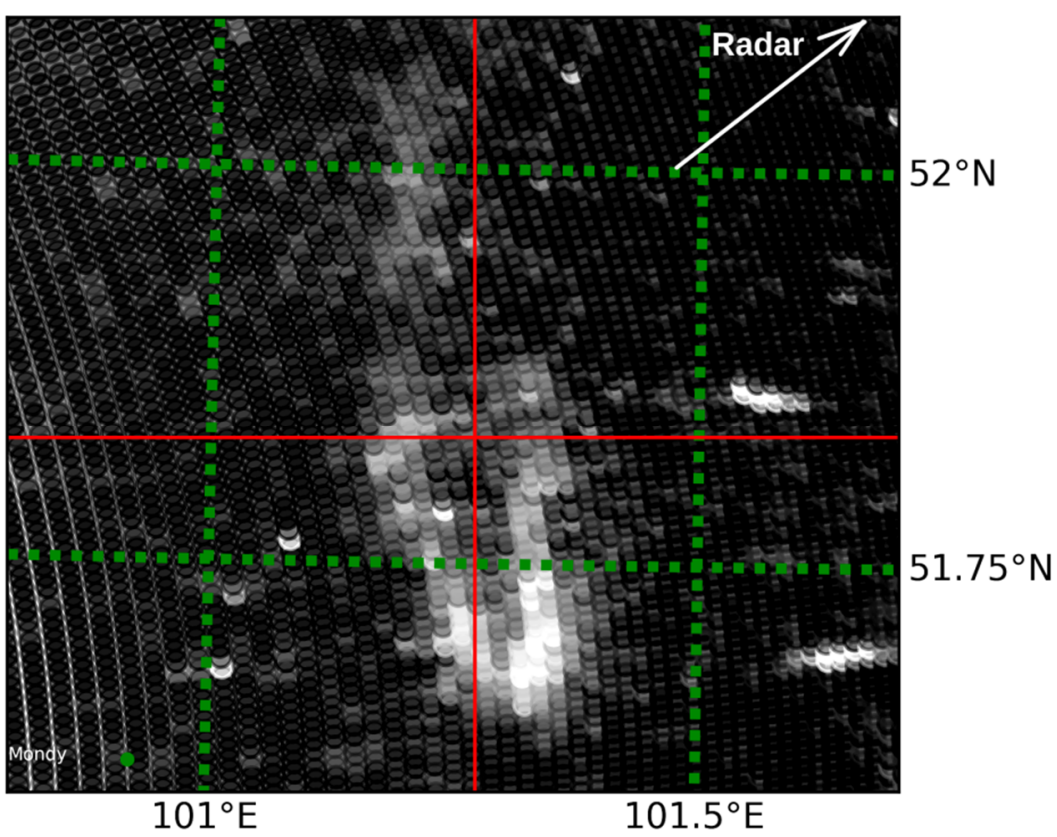

Figure 9. Projection of the KEO Sentinel image at 22.26.32 UT. Intersection of red lines shows the beginning of the meteor trail divergence. The radar is on the right.

Excitation of sodium glow results from reactions [12]:

$$
\begin{gathered}
\mathrm{Na}+\mathrm{O}_{3} \rightarrow \mathrm{NaO}+\mathrm{O}_{2} \\
\mathrm{NaO}+\mathrm{O} \rightarrow \mathrm{Na}^{*}+\mathrm{O}_{2} \\
\mathrm{Na}^{*} \rightarrow \mathrm{Na}+\mathrm{hv}
\end{gathered}
$$

causing the yellow airglow registered in Alsky-340 described in this work. The duration of the observed long-lived meteor trail was consistent with [14], which studied temporal dynamics of (6) with dependence on meteor brightness. In our case, the apparent magnitude of $-7.3 \mathrm{~m}$ as pointed to in reference [20] and accordingly with reference [14], the intensity of the trail from such a meteor should decrease to 0.1 from its initial value during about $10^{3} \mathrm{~s}$.

Also the meteoroid could contain $\mathrm{K}$, and as [12] show, the K also may participate in reactions such as (6):

$$
\begin{gathered}
\mathrm{K}+\mathrm{O}_{3} \rightarrow \mathrm{KO}+\mathrm{O}_{2} \\
\mathrm{KO}+\mathrm{O} \rightarrow \mathrm{K}^{*}+\mathrm{O}_{2} \\
\mathrm{~K}^{*} \rightarrow \mathrm{K}+h v
\end{gathered}
$$

The wavelength of the $K$ line in this case was $766.5 \mathrm{~nm}$, rather far from the band obtained by KEO Sentinel ( $\pm 1 \mathrm{~nm}$ near $630 \mathrm{~nm}$ ). Hence, the strong signal registered by KEO Sentinel as described in this work apparently did not arise from $\mathrm{K}$ airglow. As the authors of reference [12] claim: "Excitations of transitions of other meteoric elements are not possible during oxide reactions"; thus, we also ruled out the possibility of $\mathrm{Fe}, \mathrm{Al}, \mathrm{Ca}$, $\mathrm{Mg}$, or Si generating red airglow in our case.

Theoretically, the red airglow after a strong impact by a meteor can be produced from the molecular states of the main atmospheric constituents-nitrogen and oxygen and their combinations. A detailed study performed in reference [11] showed a very small contribution from such photochemical processes in long-lasting meteor trails. The possible red airglow in meteor trails was discussed later in reference [15], but the results of reference [19] ruled out that possibility and pointed instead to a strong hydroxyl component in observed long-lived meteor trails.

Excitation of the hydroxyl emission may occur due to the following reaction:

$$
\begin{aligned}
& \mathrm{H}_{2} \mathrm{O}+\mathrm{O}(1 \mathrm{D}) \rightarrow 2 \mathrm{OH} \\
& \mathrm{H}_{2} \mathrm{O}+\mathrm{O}(1 \mathrm{~S}) \rightarrow 2 \mathrm{OH}
\end{aligned}
$$


The energy balance of (8):

$$
\begin{gathered}
\Delta E_{1}=2 \Delta H_{f}^{0}(O H)-\Delta H_{f}^{0}\left(H_{2} O\right)-\Delta H_{f}^{0}(O(1 D)) \\
\Delta E_{2}=2 \Delta H_{f}^{0}(O H)-\Delta H_{f}^{0}\left(H_{2} O\right)-\Delta H_{f}^{0}(O(1 S))
\end{gathered}
$$

shows that reactions are exothermic. The values $\Delta E_{1}=-28.36 \mathrm{ccal} / \mathrm{mol}$ or $1.23 \mathrm{eV}$ and $\Delta E_{1}=-79.98 \mathrm{ccal} / \mathrm{mol}$ or $3.47 \mathrm{eV}$ are sufficient to excite the Meinel band of hydroxyl emission (9-3) through (8). A certain amount of excited oxygen atoms $O(1 D)$ and $O(1 S)$ must be present at the heights of meteor trail glows because this state results from the Barth mechanism and subsequent transition of atomic oxygen, generating airglow at $557.7 \mathrm{~nm}$ $O(1 S-1 D)$ near this height. Therefore, the $630.36 \mathrm{~nm}$ line can be registered by KEO Sentinel in long-lived meteor trails containing water. However, more detailed study of this process is needed.

Today, the water in comets, the ancestors of meteors, is considered to be one of the essential sources for the origin of the Earth's oceans. In [31], an effort was made to detect water in the constituents of comet 55P/Tempel-Tuttle from the spectral composition of the glow of a meteor from the Leonid flux. However, the authors analyzed the spectral composition of the meteor. Works describing the complex spectral composition of meteor trail glow, such as [32], considered that trails formed just after meteors with durations not exceeding several minutes. In this case, the complex spectra of the glow would be provided by the chemical composition of ablated meteor material heated by friction in the Earth's atmosphere. Therefore, reaction (8) would apparently be negligible for these conditions due to water dissociation. However, if meteor material containing relatively weakly bound water moved slowly through the upper atmosphere, as in the case of meteor dust propagation, the possibility of water emerging from the meteor material would occur, allowing reaction (8) to proceed.

\section{Conclusions}

We considered the dynamics of a unique, long-lasting meteor trail that survived for about half an hour using snapshots from wide-angle cameras and radar data obtained with meteor radar and ionosonde. Stereoscopic analysis allowed us to obtain the spatial dynamics of the trail. Further, we performed primitive spectroscopic analysis of the trail glow. The results were compared to the wind dynamics obtained with the Fabry-Perot interferometer and meteor radar at the height of the long-lived meteor trail development and its direct radar echo data. The results of earlier studies of such events were widely used, as well. Our conclusions are as follows.

The meteor shape (thickening and sharp thinning near the end with heterogeneity present) indicated that it was probably an explosion that caused meteoroid fragmentation while it was moving. Apparently, the explosion formed a cloud of solid aerosol particles (meteor dust). The shock wave and the wind field induced the cloud motion, during which the cloud trail took the shape of a spiral twisted around the normal to the Earth's surface. Aerosol formed by explosive fragmentation was concentrated at the heights of 88-106 km. Initially, during the first minutes after the explosion, the aerosol was moving in all directions at about 100-200 m/s. After a few minutes, the movement slowed down to typical wind velocities at the heights mentioned. The trail spiral shape was induced by the vertical wind shear existing at these heights during observation of the long-lasting meteor trail. This was confirmed by the background dynamics of the neutral atmosphere at the point where the long-lasting trail was observed with the Fabry-Perot interferometer and meteor radar.

The glowing meteor trail apparently consisted of sodium and hydroxyl components. The source of both components was the meteor body containing sodium and weakly bound water. The meteoroid fragmentation and production of meteor dust resulted in a $10 \mathrm{~min}$ ionization trail in the ionograms, and emanation of water from the meteor body reacted with excited oxygen atoms to produce excited hydroxyl states. The sodium airglow was 
generated as the result of a well-known process of dissociation of mesosphere ozone by $\mathrm{Na}$ atoms as a catalyst.

The obtained characteristics of the long-lasting meteor trail, especially the velocities of its expansion, differ from characteristics obtained earlier for this event in [20,21]. Therefore, the mechanisms of long-lasting meteor trail formation discussed in these papers require correction.

In our study, we described a method for detecting the spatial structure of a glowing formation using stereo images from all-sky wide-angle cameras. This method is similar to those applied by other research groups involved in the study of characteristics of gravity waves in the upper atmosphere, e.g., [33]. In addition, similar algorithms were used to determine the SAR-arc height when paired with satellite data and a network of cameras [34]. Combined with lidar, radar, and satellite data of the National Heliogeophysical Complex [35,36], this method will allow a more precise reconstruction of spatial characteristics of such events as wavelike structures, auroral arcs, meteor trails, artificial formations, etc. It is fair to assume that the accumulated statistical data on the events, together with the development of machine vision methods and neural network image processing algorithms, will allow further automation of the process as in $[23,37]$ for other applications.

Author Contributions: Data curation, R.V.V.; Formal analysis, T.E.S., A.B.B., E.G.M., M.F.A., M.V.C. and A.V.P.; Investigation, R.V.V., M.F.A. All authors have read and agreed to the published version of the manuscript.

Funding: The work was financially supported by the Ministry of Science and Higher Education of the Russian Federation (Subsidy No. 075-GZ/C3569/278) and by RFBR (grant No. 19-35-90093, grant No. 20-05-00580).

Acknowledgments: The results were obtained using the equipment of Shared Equipment Center "Angara" (http:/ / ckp-rf.ru/ckp/3056/, accessed on 29 June 2021). The authors would also like to acknowledge the three anonymous reviewers whose comments helped strengthen the content of this manuscript.

Conflicts of Interest: The authors declare no conflict of interest.

\section{References}

1. Weryk, R.J.; Brown, P.G. Simultaneous radar and video meteors-I: Metric comparisons. Planet. Space Sci. 2012, 62, 132-152. [CrossRef]

2. Weryk, R.J.; Brown, P.G. Simultaneous radar and video meteors-II: Photometry and ionisation. Planet. Space Sci. 2013, 81, 32-47. [CrossRef]

3. Brown, P.; Weryk, R.J. Coordinated optical and radar measurements of low velocity meteors. Icarus 2020, 352, 113975. [CrossRef]

4. Brown, P.; Stober, G.; Schult, C.; Krzeminski, Z.; Cooke, W.; Chau, J. Simultaneous optical and meteor head echo measurements using the Middle Atmosphere Alomar Radar System (MAARSY): Data collection and preliminary analysis. Planet. Space Sci. 2017, 141, 25-34. [CrossRef]

5. Kozlovsky, A.; Shalimov, S.; Kero, J.; Raita, T.; Lester, M. Multi-Instrumental Observations of Nonunderdense Meteor Trails. J. Geophys. Res. Space Phys. 2018, 123, 5974-5989. [CrossRef]

6. Kozlovsky, A.; Lukianova, R.; Lester, M. Occurrence and Altitude of the Long-Lived Nonspecular Meteor Trails During Meteor Showers at High Latitudes. J. Geophys. Res. Space Phys. 2020, 125, 027746. [CrossRef]

7. Bourdillon, A.; Haldoupis, C.; Hanuise, C.; Le Roux, Y.; Menard, J. Long duration meteor echoes characterized by Doppler spectrum bifurcation. Geophys. Res. Lett. 2005, 32, 1-4. [CrossRef]

8. Li, G.; Ning, B.; Chu, Y.-H.; Reid, I.M.; Hu, L.; Dolman, B.K.; Xiong, J.; Jiang, G.; Yang, G.; Yan, C. Structural evolution of long-duration meteor trail irregularities driven by neutral wind. J. Geophys. Res. Space Phys. 2014, 119, 348. [CrossRef]

9. Reddy, K.C.; Yellaiah, G. Fragmentation of specular overdense meteor trail echoes observed with Gadanki MST radar. Astrphys. Space Sci. 2016, 361, 1-8. [CrossRef]

10. Baggaley, W.; Cummack, C.; Baggaley, W.; Cummack, C. Meteor train ion chemistry. J. Atmos. Terr. Phys. 1974, 36, 1759-1773. [CrossRef]

11. Baggaley, W.J. Meteor Trains and Chemiluminescent Processes. Mon. Not. R. Astron. Soc. 1975, 173, 497-512. [CrossRef]

12. Baggaley, W.J. The Chemical Reduction of Meteoric Metal Oxides as a Source of Meteor Train Emission; Bulletin of the Astronomical Institutes of Czechoslovakia: Prague, Czech Republic, 1976; pp. 244-246.

13. Baggaley, W.J. The Role of the Oxides of Meteoric Species as a Source of Meteor Train Luminosity. Mon. Not. R. Astron. Soc. 1976, 174, 617-620. [CrossRef] 
14. Baggaley, W.J.; Cummack, C.H. The Duration of Long-Lived Meteor Trains; Bulletin of the Astronomical Institutes of Czecho-slovakia: Prague, Czech Republic, 1979; pp. 180-183.

15. Baggaley, W.J. The Red Afterglow in Meteor Wakes; Bulletin of the Astronomical Institutes of Czechoslovakia: Prague, Czech Republic, 1977; pp. 356-359.

16. Toda, M.; Yamamoto, M.; Higa, Y.; Watanabe, J. Catalogue of Persistent Trains I: Meteor Train Images during 1988-1997 and the Development of an Optimum Observation Technique. Publ. Natl. Astron. Obs. Jpn. 2004, 7, 53-66.

17. Higa, Y.; Yamamoto, M.; Toda, M.; Watanabe, J. Catalogue of Persistent Trains II: Images of Leonid Meteor Trains during the METRO Campaign 1998-2002. Publ. Natl. Astron. Obs. Jpn. 2005, 7, 67-131.

18. Kelley, M.C.; Gardner, C.; Drummond, J.; Armstrong, T.; Liu, A.; Chu, X.; Papen, G.; Kruschwitz, C.; Loughmiller, P.; Grime, B.; et al. First observations of long-lived meteor trains with resonance lidar and other optical instruments. Geophys. Res. Lett. 2000, 27, 1811-1814. [CrossRef]

19. Clemesha, B.R.; de Medeiros, A.F.; Gobbi, D.; Takahashi, H.; Batista, P.P.; Taylor, M.J. Multiple wavelength optical ob-servations of a long-lived meteor trail. Geophys. Res. Lett. 2001, 28, 2779-2782. [CrossRef]

20. Ivanov, К.; Комарова, Е.; Васильев, Р.; Еселевич, М.; Михалев, А.; Komarova, E.; Vasilyev, R.; Eselevich, M.; Mikhalev, A.; Иванов, К. Meteor trail drift research based on baseline observations. Solar-Terr. Phys. 2019, 5, 77-81. [CrossRef]

21. Михалев, А.; Mikhalev, А.; Белецкий, А.; Beletsky, А.; Васильев, Р.; Vasilyev, R.; Еселевич, M.; Eselevich, M.; Koмарова, Е.; Komarova, E.; et al. Long-lived meteor trails. Solar-Terr. Phys. 2019, 5, 109-116. [CrossRef]

22. Lang, D.; Hogg, D.; Mierle, K.; Blanton, M.; Roweis, S. Astrometry.net: Blind astrometric calibration of arbitrary astronomical images. Astron. J. 2010, 139, 1782-1800. [CrossRef]

23. Danescu, R.; Oniga, F.; Turcu, V.; Cristea, O. Long Baseline Stereovision for Automatic Detection and Ranging of Moving Objects in the Night Sky. Sensors 2012, 12, 12940-12963. [CrossRef]

24. Ceplecha, C. Geometric, Dynamic, Orbital and Photometric Data on Meteoroids from Photographic Fireball Networks; Bulletin Astrnomical Institutes of Czechoslovakia: Prague, Czech Republic, 1987; p. 222.

25. Borovička, J.; Spurný, P.; Keclíková, J. A new positional astrometric method for all-sky camera. Astron. Astrophys. Suppl. Ser. 1995, $112,173$.

26. Borovička, J.; Štork, R.; Boček, J. First results from video spectroscopy of 1998 Leonid meteors. Meteorit. Planet. Sci. 1999, 34, 987-994. [CrossRef]

27. Bannister, S.M.; Boucheron, L.E.; Voelz, D.G. A Numerical Analysis of a Frame Calibration Method for Video-based All-Sky Camera Systems. Publ. Astron. Soc. Pac. 2013, 125, 1108-1118. [CrossRef]

28. Moré, J.J. The Levenberg-Marquardt algorithm: Implementation and theory. In Numerical Analysis; Springer: Berlin/Heidelberg, Germany, 1978; pp. 105-116.

29. Sheese, P.E.; Llewellyn, E.J.; Gattinger, R.L.; Strong, K. OH Meinel band nightglow profiles from OSIRIS observations. J. Geophys. Res. Atmos. 2014, 119, 417. [CrossRef]

30. Васильев, P.; Artamonov, М.; Белецкий, А.; Beletsky, А.; Жеребцов, Г.; Zherebtsov, G.; Medvedeva, I.; Михалев, А.; Сыренова, Т. Registering upper atmosphere parameters in East Siberia with Fabry-Perot Interferometer KEO Scientific "Arinae". Solar-Terr. Phys. 2017, 3, 61-75. [CrossRef]

31. Jenniskens, P.; Laux, C.O. Search for the $\mathrm{OH}(\mathrm{X} 2 \Pi)$ Meinel Band Emission in Meteors as a Tracer of Mineral Water in Comets: Detection of N2+ (A-X). Astrobiology 2004, 4, 109-121. [CrossRef]

32. Abe, S.; Ebizuka, N.; Murayama, H.; Ohtsuka, K.; Sugimoto, S.; Yamamoto, M.-Y.; Yano, H.; Watanabe, J.-I.; Borovička, J. Video and photographic spectroscopy of 1998 and 2001 leonid persistent trains from 300 to $930 \mathrm{~nm}$. Earth Moon Planets 2005, 95, 265-277. [CrossRef]

33. Kouahla, M.; Moreels, G.; Faivre, M.; Clairemidi, J.; Meriwether, J.; Lehmacher, G.; Vidal, E.; Veliz, O. 3D Imaging of the OH mesospheric emissive layer. Adv. Space Res. 2010, 45, 260-267. [CrossRef]

34. Gillies, D.M.; Knudsen, D.; Donovan, E.; Jackel, B.; Gillies, R.; Spanswick, E. Identifying the 630 nm auroral arc emission height: A comparison of the triangulation, FAC profile, and electron density methods. J. Geophys. Res. Space Phys. 2017, 122, 8181-8197. [CrossRef]

35. Zherebtsov, G. Complex of heliogeophysical instruments of new generation. Solar-Terr. Phys. 2020, 6, 3-13. [CrossRef]

36. Vasilyev, R.; Artamonov, M.; Beletsky, A.; Zorkaltseva, O.; Komarova, E.; Medvedeva, I.; Mikhalev, A.; Podlesny, S.; Ratovsky, K.; Syrenova, T.; et al. Scientific goals of optical instruments of the National Heliogeophysical Complex. Solar-Terr. Phys. 2020, 6, 84-97. [CrossRef]

37. Whiter, D.K.; Gustavsson, B.; Partamies, N.; Sangalli, L. A new automatic method for estimating the peak auroral emission height from all-sky camera images. Geosci. Instrum. Methods Data Syst. 2013, 2, 131-144. [CrossRef] 